Article

\title{
Production of Geopolymeric Mortars Containing Forest Biomass Ash as Partial Replacement of Metakaolin
}

\author{
Sebastiano Candamano ${ }^{1, *}$, Pierantonio De Luca ${ }^{1, *}$, Patrizia Frontera ${ }^{2}$ (D) and Fortunato Crea ${ }^{1}$ \\ 1 Department of Environmental and Chemical Engineering, University of Calabria, \\ Rende, Cosenza 87036, Italy; fortunato.crea@unical.it \\ 2 Department of Civil Engineering, Energy, Environmental and Materials, \\ Mediterranea University of Reggio Calabria, Reggio Calabria 89122, Italy; patrizia.frontera@unirc.it \\ * Correspondence: sebastiano.candamano@unical.it (S.C.); pierantonio.deluca@unical.it (P.D.L.); \\ Tel.: +39-0984-496701 (S.C.); +39-0984-496757 (P.D.L.)
}

Received: 11 September 2017; Accepted: 11 October 2017; Published: 15 October 2017

\begin{abstract}
Geopolymers are a new class of binders based on alkali activation of natural and by-products raw materials. Their properties and eco-compatibility highly depends on the reaction system. The $(\mathrm{Na}, \mathrm{K})_{2} \mathrm{O}-\mathrm{Al}_{2} \mathrm{O}_{3}-\mathrm{SiO}_{2}-\mathrm{H}_{2} \mathrm{O}$ system shows a distinguishing pseudo-zeolitic network structure, but reaction requires a high amount of activators. The aim of this work is to investigate how the use of forest biomass ash (FBA), as partial replacement material in the production of metakaolin (MK) based geopolymeric mortar, and affect its properties. FBA is a by-product of the combustion process of forest biomass in thermal power plants. Mortars with a FBA content of $0 \%, 10 \%, 20 \%$, and $30 \%$ wt have been tested for workability, flexural, and compressive strength. Capillary absorption, micro-morphological features, thermal, and shrinkage behavior have been investigated. The addition of FBA allowed for a decrease in the use of alkaline activator up to $20 \%$, while preserving the characteristic broad hump centered at approximately $28^{\circ} 2 \theta$ Mechanical properties of the geopolymeric mortars decrease proportionally with metakaolin replacement, even if a compression strength of more than $35 \mathrm{MPa}$ is still obtained with a FBA content of $30 \% \mathrm{wt}$. After thermal cycles of up to $700{ }^{\circ} \mathrm{C}$, all of the mortars still retain their cohesiveness, with an overall loss of mechanical strength of about $80 \%$ of the initial value that can be attributed to the formation of microcracks as a consequence of the network strain and distortion due to dehydration and shrinkage.
\end{abstract}

Keywords: forest biomass ash; geopolymeric mortar; workability; mechanical properties; capillary water absorption

\section{Introduction}

The use of forest biomass as fuel in thermal power plants is becoming a common practice due to its availability, low cost, sustainability, and renewability. The process of combustion, which significantly reduces the mass of the forest biomass, leads to the production of fine FBA as by-product in the range of $6-10 \%$ [1]. In order to further increase the environmental sustainability of the process, it is necessary to reduce the fraction of forest biomass ash (FBA) that is currently land-filled. To achieve this target, new application fields, different from soil amendment, have to be found [2-4]. Furthermore, the development of more environmentally friendly materials based on the utilization of industrial waste materials or recycled materials in their manufacture is a nowadays focus. It allows for reducing natural raw materials, water, and energy consumption, and it is driven by the increasingly more stringent environmental regulations $[5,6]$.

Recently the properties of a new class of binders, the geopolymers [7], have been investigated by several studies [8,9]. Their eco-compatibility strongly depends on both the raw materials and the 
amount and concentration and type of alkaline activator solution used. Mix designs that contains high amount of industrial by-product (such as activated slag and fly ash) or natural raw materials (volcanic tuff) are commonly labeled as "blended or hybrid alkaline" cements, that are eco-friendly, cure at ambient temperature, and use a low amount alkaline activator [10]. Nevertheless, many problems remain, such as relevant shrinkage, efflorescence, and a lack of specific additives to regulate properties. When exclusively aluminosilicate sources, such as metakaolin, are used as reactive powder, hardening requires heat and high amount of sodium silicate activators. $(\mathrm{Na}, \mathrm{K})_{2} \mathrm{O}-\mathrm{Al}_{2} \mathrm{O}_{3}-\mathrm{SiO}_{2}-\mathrm{H}_{2} \mathrm{O}$ system (low calcium system), is expensive and not strictly appropriate to mitigate greenhouse gas emissions, but it still can be marketed, because of its peculiar pseudo-zeolitic network structure, for special niche applications, such as in ion exchange processes [11,12], catalysis [13-15], as adsorbent [16], and others $[17,18]$. The aim of this work is to study the feasibility to use forest biomass ash as partial replacement material in the production of metakaolin (MK) based geopolymeric mortars in order to decrease the consumption of metakaolin (obtained by calcination), while simultaneously allowing to:

1. Decrease the amount of sodium silicate solution used;

2. Preserve the three-dimensional amorphous network built from $\mathrm{TO}_{4}(\mathrm{~T}=\mathrm{Si}, \mathrm{Al})$ tetrahedral, joined at the corners with oxygen;

3. Guarantee adequate mechanical properties.

Specific goals of the research were: (1) to characterize FBA in terms of chemical composition, mineralogic phases, morphology by Energy Dispersive Spectroscopy (EDS), X-ray Diffraction (XRD) and Scanning Electron Microscope (SEM) analysis; (2) to evaluate the fresh state and mechanical properties, capillary absorption, shrinkage, and thermal behavior of mortars containing $0 \%, 10 \%, 20 \%$, $30 \% \mathrm{wt}$ of FBA as partial replacement of metakaolin.

\section{Materials and Methods}

\subsection{Materials}

\subsubsection{Metakaolin, Sodium Silicate Solition and Sodium Hydroxide}

Metakaolin with an average particles size of $1.59 \mu \mathrm{m}$ has been supplied by Personal Factory S.p.a. (Simbario, Italy). The mass compositions of metakaolin, obtained by X-ray fluorescence, and of sodium silicate solution (supplied by Sasol Italy S.P.A (Milan, Italy)) are listed in Table 1. Sodium Hydroxide (analytical reagents grade) has been purchased by Sigma Aldrich (Milano, Italy).

Table 1. Chemical composition of raw materials.

\begin{tabular}{ccc}
\hline Component (\%wt) & Metakaolin & Sodium Silicate Solution \\
\hline $\mathrm{Al}_{2} \mathrm{O}_{3}$ & 42.02 & - \\
$\mathrm{SiO}_{2}$ & 53.9 & 29.6 \\
$\mathrm{~K}_{2} \mathrm{O}$ & 0.30 & - \\
$\mathrm{Na}_{2} \mathrm{O}$ & 0.09 & 13.76 \\
$\mathrm{Fe}_{2} \mathrm{O}_{3}$ & 1.52 & - \\
$\mathrm{TiO}_{2}$ & 1.90 & - \\
$\mathrm{MgO}$ & - & - \\
$\mathrm{P}_{2} \mathrm{O}_{5}$ & - & - \\
$\mathrm{CaO}$ & - & - \\
$\mathrm{SO}$ & - & - \\
$\mathrm{MnO}$ & - & - \\
$\mathrm{LO}$ & 1.00 & - \\
$\mathrm{H}_{2} \mathrm{O}$ & - & 56.78 \\
\hline
\end{tabular}




\subsubsection{Forest Biomass Ash}

FBA, having a D10 of $11.72 \mu \mathrm{m}$, a D50 of $30.16 \mu \mathrm{m}$, and a D90 of $61.47 \mu \mathrm{m}$ have been provided by a local plant. Its chemical composition has been obtained by Energy Dispersive X-ray analysis (EDX) and reported in Figure 1. Morphology of FBA has been examined on a scanning electron microscope (FEI Company model Inspect).

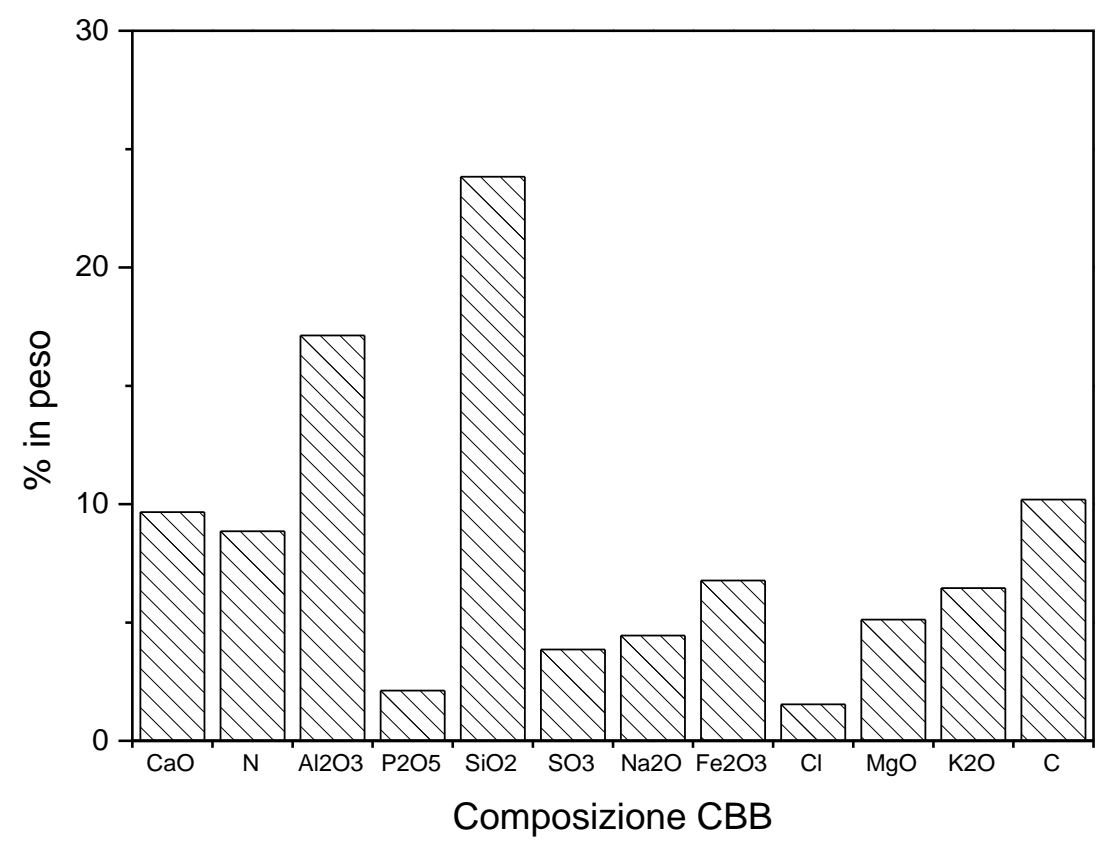

Figure 1. Forest biomass ash (FBA) average composition in terms of oxides.

\subsubsection{Aggregates}

The fine, quarzitic aggregates, having a D10 of $0.25 \mathrm{~mm}$, a D50 of $0.5 \mathrm{~mm}$, and a D90 of $2.25 \mathrm{~mm}$ with a maximum diameter of $2.75 \mathrm{~mm}$, are locally sourced. Before being used, they were dried to saturated surface dry condition.

\subsection{Methods}

\subsubsection{Mixture Proportioning and Mixing}

All of the mortar mixes have been prepared by maintaining constant the water/binder and sand/binder ratios at 0.53 and 2.8, respectively. The water/binder ratio has been chosen to ensure an adequate workability. The metakaolin binder was partially replaced by FBA at levels of $10 \%, 20 \%$, and $30 \%$ wt. The maximum replacement has been selected so that the weight of $\mathrm{SiO}_{2}$ and $\mathrm{Al}_{2} \mathrm{O}_{3}$ in the binder is at least about $80 \%$. This value and a Si / $\mathrm{Al}$ molar ratio about 2 in the geopolymeric mixture are considered benchmark values to obtain a structural geopolymeric mortar $[18,19]$. The compositions of mortar mixtures are summarized in Table 2.

Table 2. Mix proportions.

\begin{tabular}{ccccccc}
\hline Mix No. & W/B (wt) & $\mathbf{S i O}_{\mathbf{2}} / \mathbf{A l}_{\mathbf{2}} \mathbf{O}_{\mathbf{3}}$ (molar) & $\mathbf{N a}_{\mathbf{2}} \mathbf{O} / \mathbf{A l}_{\mathbf{2}} \mathbf{O}_{\mathbf{3}}$ (molar) & $\mathbf{F B A} /$ Binder (wt) & Sand/Binder (wt) & $\begin{array}{c}\text { B: Alkali Silicate Solution } \\
\text { (dry basis) (wt) }\end{array}$ \\
\hline $0 \mathrm{~S}$ & 0.53 & 3.8 & 1 & 0 & 2.8 & $1.35: 1$ \\
$10 \mathrm{~S}$ & 0.53 & 3.8 & 1 & 0.1 & 2.8 & $1.45: 1$ \\
$20 \mathrm{~S}$ & 0.53 & 3.8 & 1 & 0.2 & 2.8 & $1.55: 1$ \\
$30 \mathrm{~S}$ & 0.53 & 3.8 & 1 & 0.3 & 2.8 & $1.7: 1$ \\
\hline
\end{tabular}


All of the geopolymeric batches followed the same mixing sequence, speed, and time. Metakaolin, FBA were first mechanically mixed for $2 \mathrm{~min}$, and then the alkali activator solution, containing sodium silicate solution, sodium hydroxide, and distilled water has been added. The so obtained slurry was mixed for $10 \mathrm{~min}$ and finally fine sand was added. After a further $5 \mathrm{~min}$ of mixing batch was transferred to prismatic moulds with dimensions of $40 \times 40 \times 160 \mathrm{~mm}$ and cured for $1 \mathrm{~h}$ at $50{ }^{\circ} \mathrm{C}$ and then at an ambient temperature and pressure.

\subsubsection{Workability}

Flow tests were performed on fresh mortars mixes using the flow table and according to UNI EN 1015-3 [20].

\subsubsection{Mechanical Strength}

Compressive and flexural strengths have been determined on prismatic specimens with dimensions of $4 \times 4 \times 16 \mathrm{~mm}$ after 2, 7, 28 days of curing according to UNI-EN 196-1:2005 [21]. All of the values have been obtained as the average of three numbers of specimens tested.

\subsubsection{Capillary Water Absorption}

Transport properties of mortar surface determine its durability. In the present study, capillary water absorption tests have been carried out according to UNI EN 1015-1 [22]. The specimens have been dried in a ventilated oven at $50^{\circ} \mathrm{C}$ until a constant mass has been achieved. After cooling at $20^{\circ} \mathrm{C}$, all of the specimens were put on rods in a shallow bath of water a $20^{\circ} \mathrm{C}$, at a depth of about $3 \mathrm{~mm}$.

The uptake of water by capillary absorption was measured through the weight gain of each specimen at regular intervals of immersion. The equation used to model the absorption of water due to capillary action is the following [22,23]:

$$
\mathrm{A}=\mathrm{a}_{0}+\mathrm{St}^{0.5}
$$

where $\mathrm{A}\left(\mathrm{mg} / \mathrm{mm}^{2}\right)$ is the water absorption by unit area since the dipping in water; $\mathrm{S}\left(\mathrm{mg} /\left(\mathrm{mm}^{2} \times \mathrm{min}^{0.5}\right)\right)$ is the sorptivity of the material; and, $t$ is the elapsed time in minutes and $a_{0}\left(\mathrm{mg} / \mathrm{mm}^{2}\right)$ is the water initially absorbed by pores in contact with water.

\subsubsection{Shrinkage Test}

Drying shrinkage measurements of selected alkali-activated geopolymeric mortar mixes have been carried out at 6-months, according to relevant standard EN 12617-4:03 [21].

\subsubsection{Thermal Cycles}

Thermal tests have been performed on geopolymeric mortars with the replacement of metakaolin with FBA by exposing them for various thermal cycles at different temperatures, after a curing period of 28 days. The degradation of mechanical properties has been evaluated by the non-destructive ultrasonic reflection technique. The compressive strength before and after thermal cycles have been also measured and compared. XRD diffractrograms have been collected on a Rigaku MiniFlex 600 X-ray diffractometer (Rigaku Corporation, Tokyo, Japan) diffractometer with $\mathrm{CuK} \alpha$, radiation generated at $20 \mathrm{~mA}$ and $40 \mathrm{KV}$. Typical specimens have been scanned from $5-50^{\circ}$ at $0.022 \theta$ steps integrated at a rate of $0.5 \mathrm{~s}$.

\section{Results and Discussion}

XRD analysis of FBA, (not shown), reveals the presence of both amorphous and crystalline phases, the predominant crystalline phase being quartz. Micrographs of FBA at different magnifications, reported in Figure 2, show that FBA is a heterogeneous mixture of particles of varying sizes and 
morphologies, both irregular and spherical. FBA are highly alkaline so they may lead to a favorable acceleration of geopolymerization process (Tables 3 and 4).
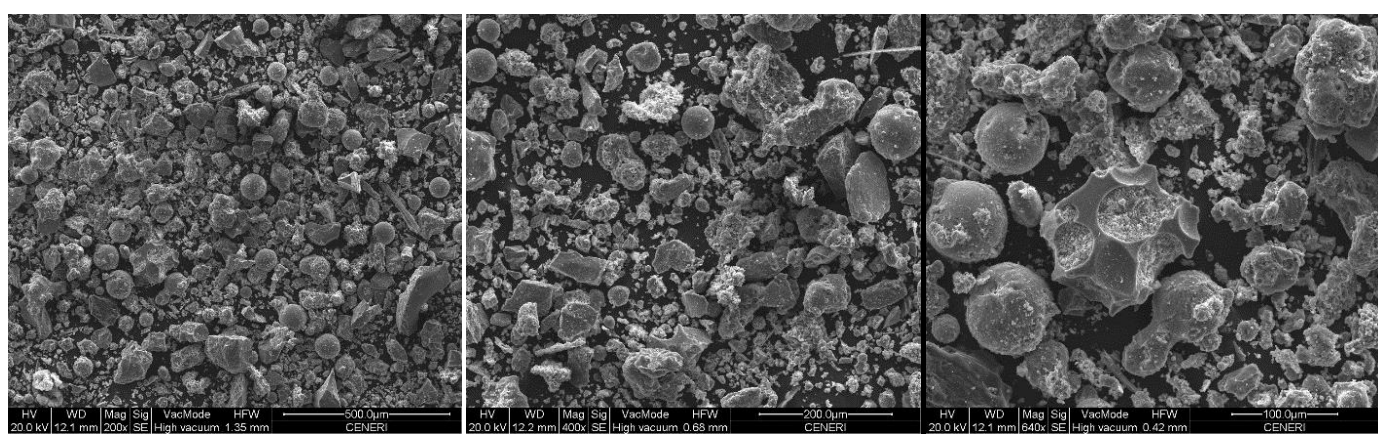

Figure 2. SEM micrographs of FBA at different magnifications.

Table 3. Solution proportions.

\begin{tabular}{cccc}
\hline Time $(\mathbf{m i n})$ & $\mathbf{H}_{\mathbf{2}} \mathbf{O}$ Dis $\mathbf{( g )}$ & FBA $(\mathbf{g})$ & Metakaolin $(\mathbf{g})$ \\
\hline Solution 1 & 50 & 5 & 0 \\
Solution 2 & 50 & 0 & 5 \\
\hline
\end{tabular}

Table 4. Solution $\mathrm{pH}$ at different times.

\begin{tabular}{ccc}
\hline Time (min) & pH Solution $\mathbf{1}$ & pH Solution 2 \\
\hline 1 & 12.54 & 6.315 \\
5 & 12.82 & 6.375 \\
10 & 12.85 & 6.387 \\
\hline
\end{tabular}

The workability was evaluated quantitatively by the consistency measured through the flow table test. The inclusion of FBA as a partial replacement material in geopolymeric mortar resulted in an increasing of workability, as shown in Figure 3. This behavior can be ascribed to both an increased rate in the dissolution of metakaolin due to the higher alkalinity of the reaction mixes containing FBA, and the greater FBA average particles size than metakaolin. In fact, alkalinity has the great influence in the reaction medium on the dissolution rate of metakaolin.

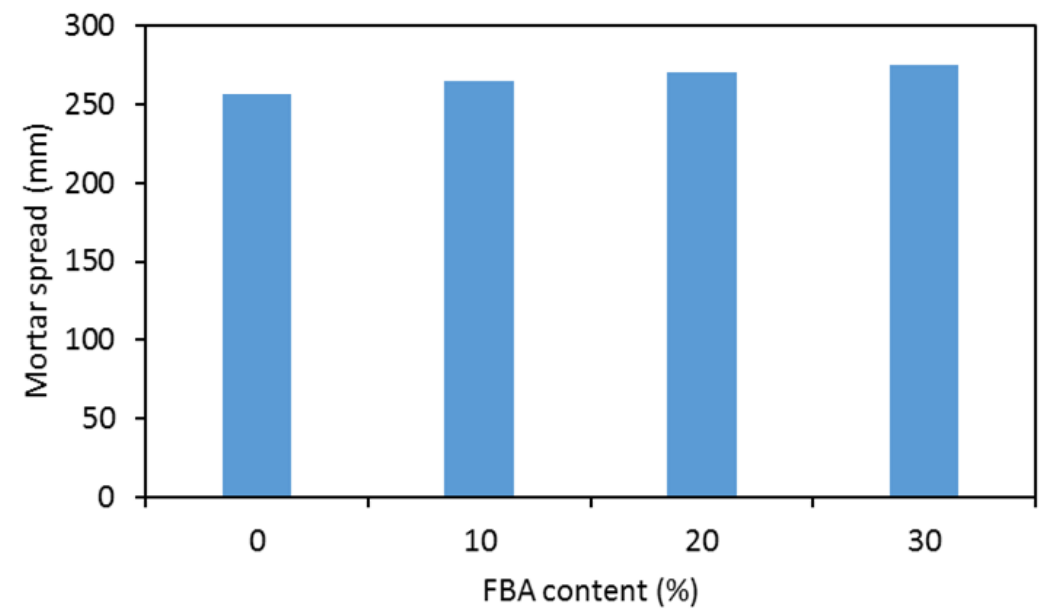

Figure 3. Average spread flow vs FBA content. 
Figure 4 shows the XRD patterns of metakaolin raw source (a) as well as of the synthesized geopolymeric mortars with different FBA contents.

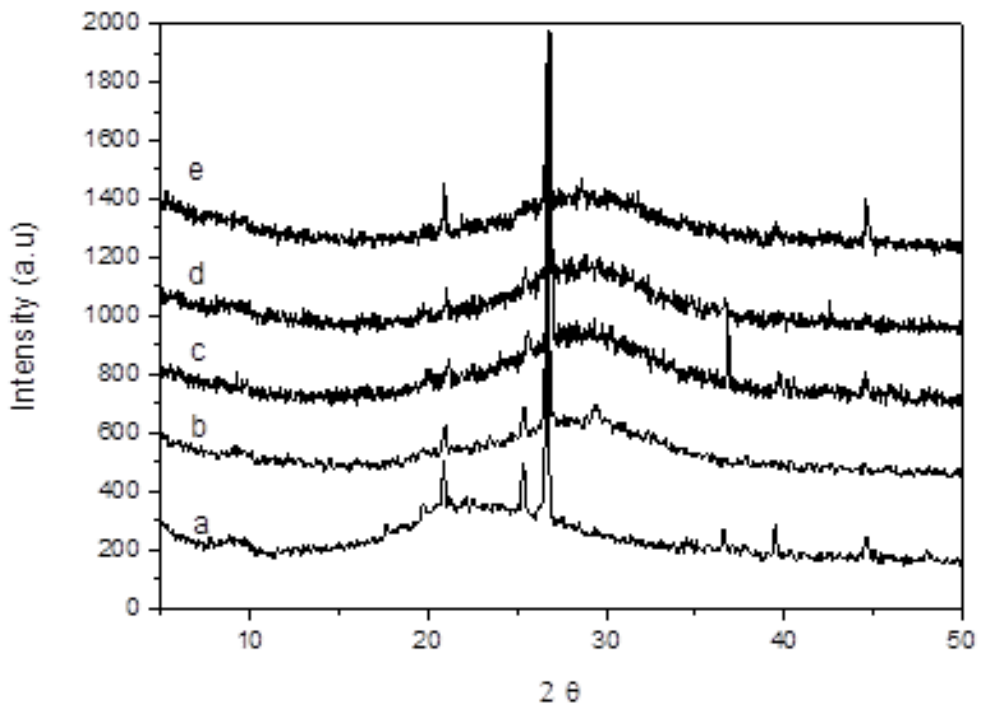

Figure 4. Diffractograms (a) Metakaolin; geopolymeric mortars cured at $50{ }^{\circ} \mathrm{C}$ : (b) $0 \%$ wt FBA, (c) $10 \%$ wt FBA (d) $20 \%$ wt FBA (e) $30 \%$ wt FBA.

Metakaolin exhibits a pronounced broad hump centered at approximately $22^{\circ} 2 \theta$ with few peaks, indicating that it contains essentially amorphous silica and alumina with crystalline phases such as quartz [19]. For the manufactured geopolymeric mortars, the characteristic broad hump centered at approximately $28^{\circ} 2 \theta$ is observed, regardless of FBA content. It can be considered as the distinguishing feature of the diffractogram of any geopolymer [15].

Furthermore, when comparing the XRD patterns of the raw materials and cured geopolymers, the overlapping of the peaks of the crystalline phases clearly results. Thus, it can be stated that they do not participate to the geopolymerization process. As a consequence, the use of parent materials mainly containing reactive amorphous phases is of primary importance to obtain geopolymers with acceptable mechanical properties.

The micro-morphological features of the parent material and geopolymers with different FBA contents are compared in Figure 5a-c.
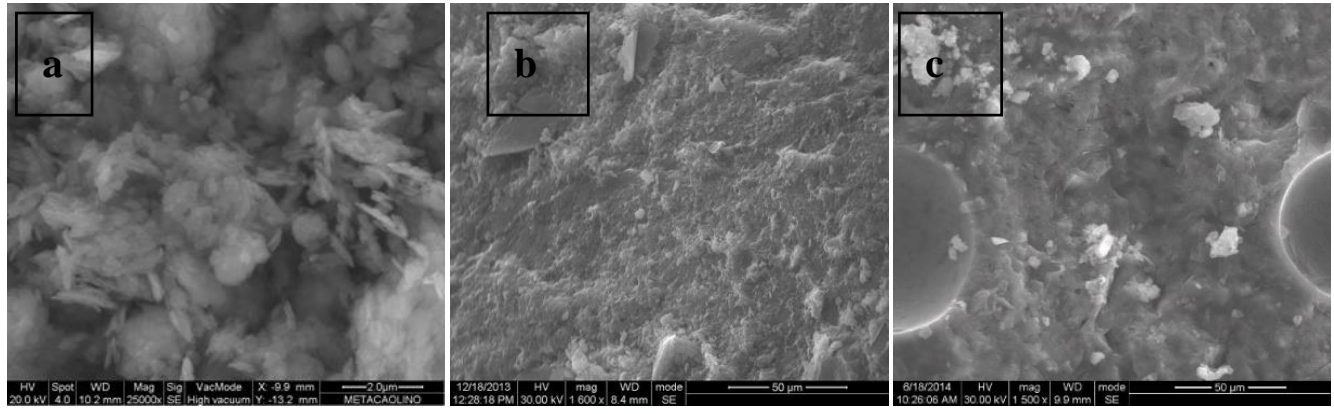

Figure 5. SEM micrographs of (a) Metakaolin and geopolymeric mortars cured at $50{ }^{\circ} \mathrm{C}$ with (b) $0 \%$ wt FBA, and (c) $30 \%$ wt FBA.

Metakaolin particles are dominantly plate in shape, instead the obtained geopolymers mortars show a continuous gel-like matrix with few clear particles or particle boundaries. 
Furthermore, geopolymeric mortars with FBA show a more porous and patchy matrix with some unreacted spherical ash particles.

Figure 6 compares the values of the compressive and flexural strength of geopolymeric mortars with different content of FBA, after 2, 7, 28 days of curing at ambient temperature.

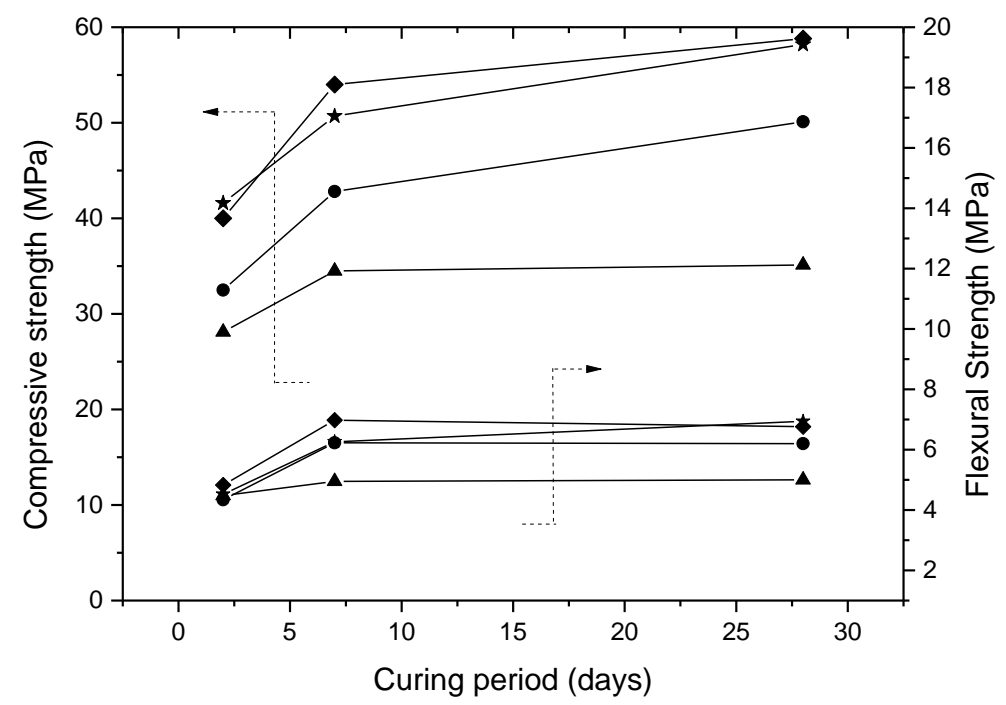

Figure 6. Flexural and compressive strength vs curing days at different FBA contents: $\downarrow 0 \%$; $\star 10 \%$; ๑20\%; $\mathbf{\Delta} 30 \%$.

The use of FBA at a level of replacement of $10 \%$ wt does not affect the mechanical properties of the geopolymeric mortars, while higher replacements proportionally reduce the compressive and flexural strength of the mortars, for all of the curing times. Furthermore, when the highest amount of FBA is used, ultimate mechanical properties are reached after seven days of curing. The observed decline in strength can be attributed to the decrease of the amount of soluble $\mathrm{Si}$ and $\mathrm{Al}$ in mixtures that is around $96 \%$ wt of binder composition when only metakaolin is used and around $80 \%$ when the maximum amount of ashes is used. Nevertheless, at the lowest level of replacement the increased alkalinity of the reaction medium due to FBA, positively affects the dissolution extend of metakaolin, thus allowing to compensate the lower amount of soluble $\mathrm{Si}$ and $\mathrm{Al}$ in the mixture. At the highest level of replacement, even if compensation is no more possible, thus measuring a compression strength of $35 \mathrm{MPa}$, the increased alkalinity and the lower amount of metakaolin allow an acceleration of the dissolution rate and condensation reactions between aluminate and silicate species [24-26], with final compressive and flexural strengths already being reached after 7 days of curing. Other aspects to be pointed out are that the prepared mortars have shown a compressive strength ranging between 27 and $42 \mathrm{MPa}$ after two day of curing.

Figure 7 shows that mortars with no replacement of metakaolin exhibit a greater resistance to water absorption by capillary suction than the mortars containing FBA. Sorptivity $(S)$ is a material property, which characterizes the tendency of a porous material to absorb and transmit water by capillarity. Its value can be influenced by several factors, such as W/B ratio, curing method and time, drying conditions, admixture type, and replacement quantity. Since all of these factors have been kept constant except the replacement quantity, variation of the sorptivity values can be ascribed to FBA content. 


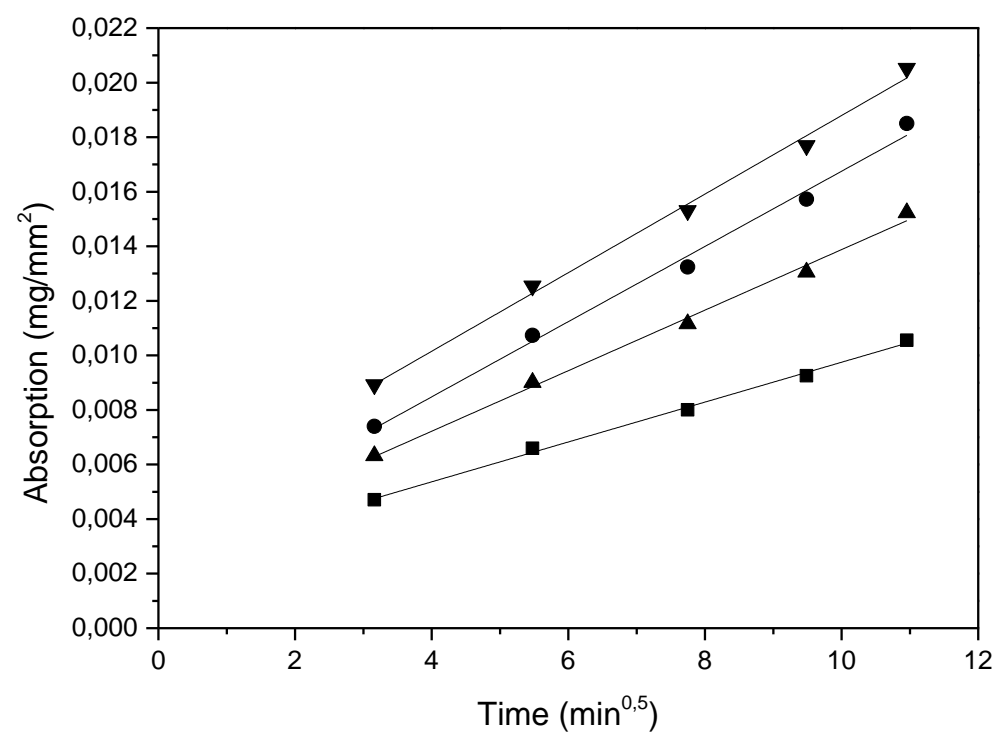

Figure 7. Capillary absorption vs time at different FBA contents: $0 \% ; \mathbf{\Delta} 10 \% ; 020 \%$; $30 \%$.

As it can be seen from Table 5, sorptivities values increase with increasing the FBA content.

Table 5. Sorptivity values as obtained by experimental data fitted using equation 1.

\begin{tabular}{ccccc}
\hline Mix No. & Eq. $y=\mathbf{S} x+\mathbf{a}$ & $\mathbf{S}$ & $\mathbf{a}$ & $\mathbf{R}^{\mathbf{2}}$ \\
\hline OS & $7.307 \mathrm{E}-4$ & 0.00244 & 0.996 \\
10S & 0.00111 & 0.00278 & 0.994 \\
20S & & 0.00138 & 0.00297 & 0.991 \\
30S & 0.00144 & 0.00439 & 0.994 \\
\hline
\end{tabular}

This suggests that FBA alters the structure of the pores and the interconnected capillary pores. This also offers another element for the interpretation of the obtained mechanical data. This occurrence could also affect durability [27].

In Figure 8, the drying shrinkage properties of selected mortars and their weight loss are reported.

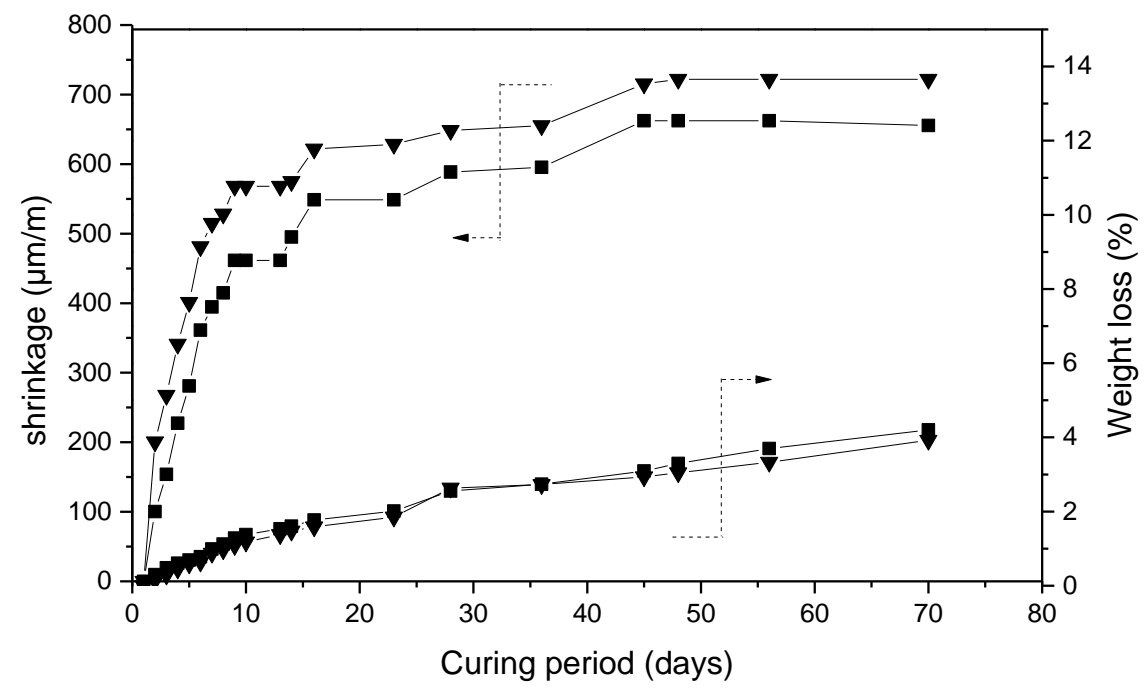

Figure 8. Drying shrinkage and weight loss vs curing days at selected FBA contents: 
From the results, it can be observed that the samples exhibited similar behavior and that the inclusion of FBA slightly increases both the drying shrinkage and weight loss, as a consequence of the increased porosity.

Thermal stability of the prepared mortars has been also investigated. In Figures 9 and 10 the residual weight and the propagation velocities of ultrasonic pulse transmitted through the hardened mortars after thermal treatments at different temperatures are reported.

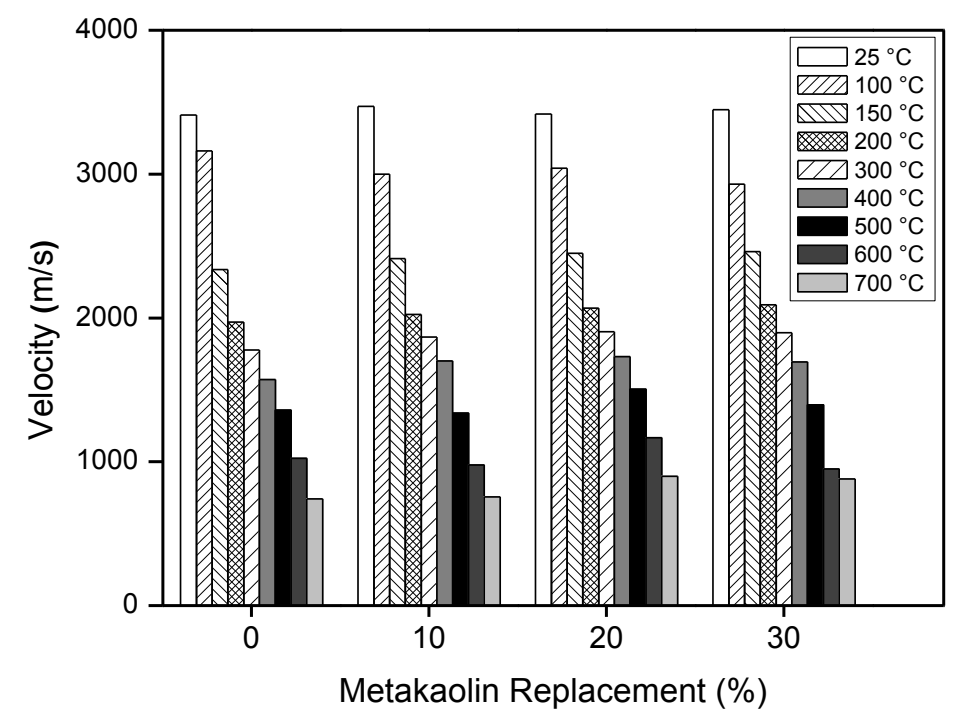

Figure 9. Propagation velocities of ultrasonic pulse vs temperature at different FBA contents.

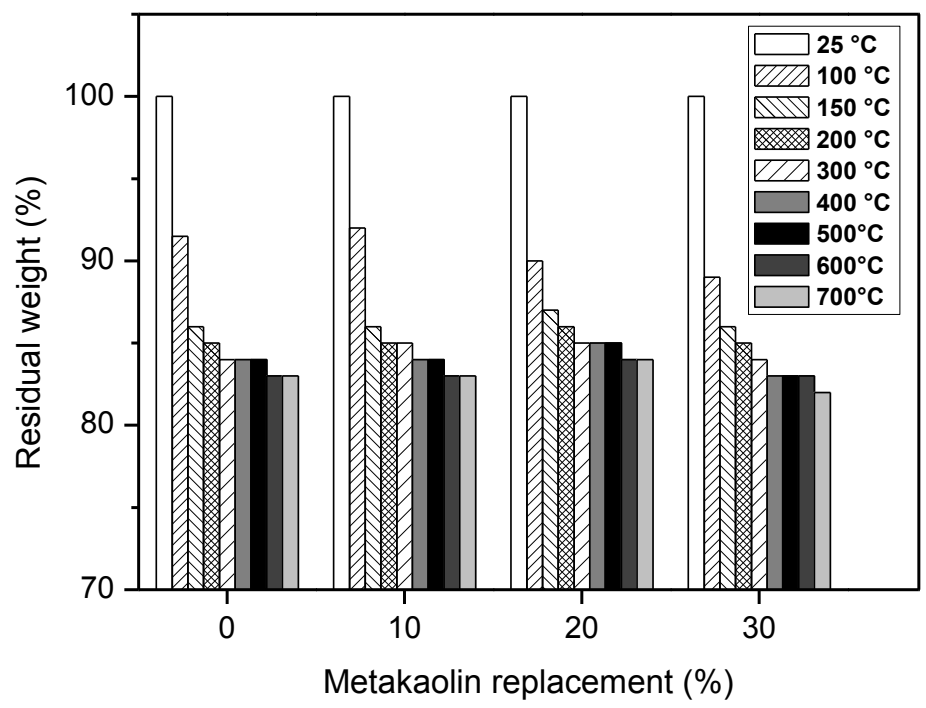

Figure 10. Residual weight and propagation vs temperature at different FBA contents.

All of the mortars showed similar behaviour. They dehydrate at a high rate up to $150{ }^{\circ} \mathrm{C}$, then slowing down and reaching a final asymptotic value that ranges from $82-84 \%$ of the initial specimens' weight.

Also, ultrasonic pulse velocities decreased after each thermal treatment and two regions can be clearly defined, the first up to $200^{\circ} \mathrm{C}$, with a higher slope.

The observed regions are in accordance with both the mass loss due dehydration, as already observed [28], and the formation of micro-cracks, as also confirmed by microstructural features of geopolymers with a FBA content of $0 \%$ and a $30 \% \mathrm{wt}$ (Figure 11). At microscale, cracks are visible on 
both the samples, with particles forming a layer-like structure, which results less dense in geopolymer mortar prepared with FBA.
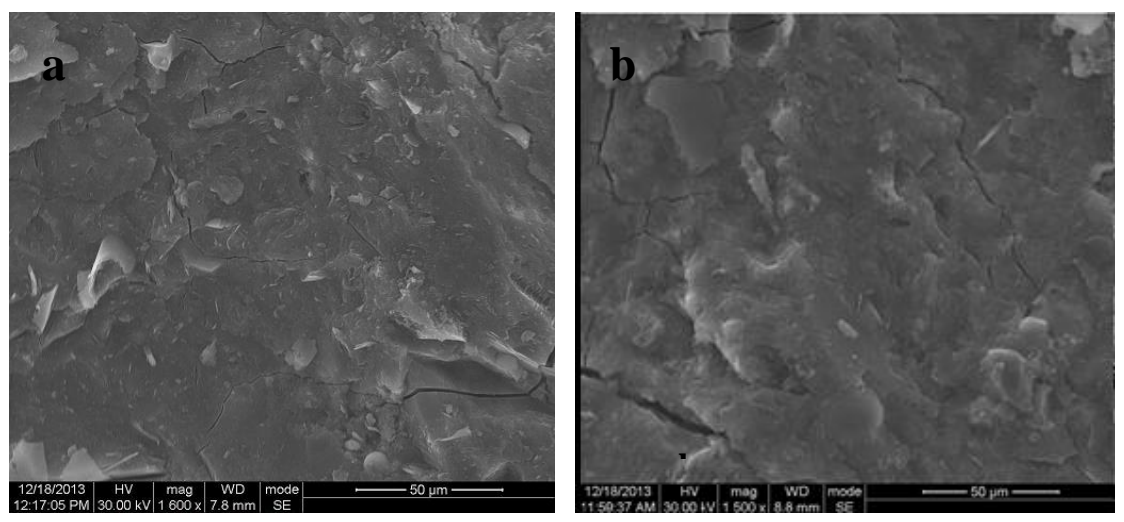

Figure 11. SEM micrographs of geopolymer mortars after thermal treatments up to $700{ }^{\circ} \mathrm{C}$ (a) $0 \% \mathrm{wt}$, (b) $30 \%$ wt of FBA.

The results of heating cycles, in terms of XRD patterns, are reported in Figure 12A,B for a FBA content of $0 \%$ and $30 \%$, respectively. The broadening of the main feature in geopolymers diffractograms with the increasing of temperature can be attributed to network strain and distortion due to dehydration and shrinkage of the geopolymer network as elsewhere reported [29].
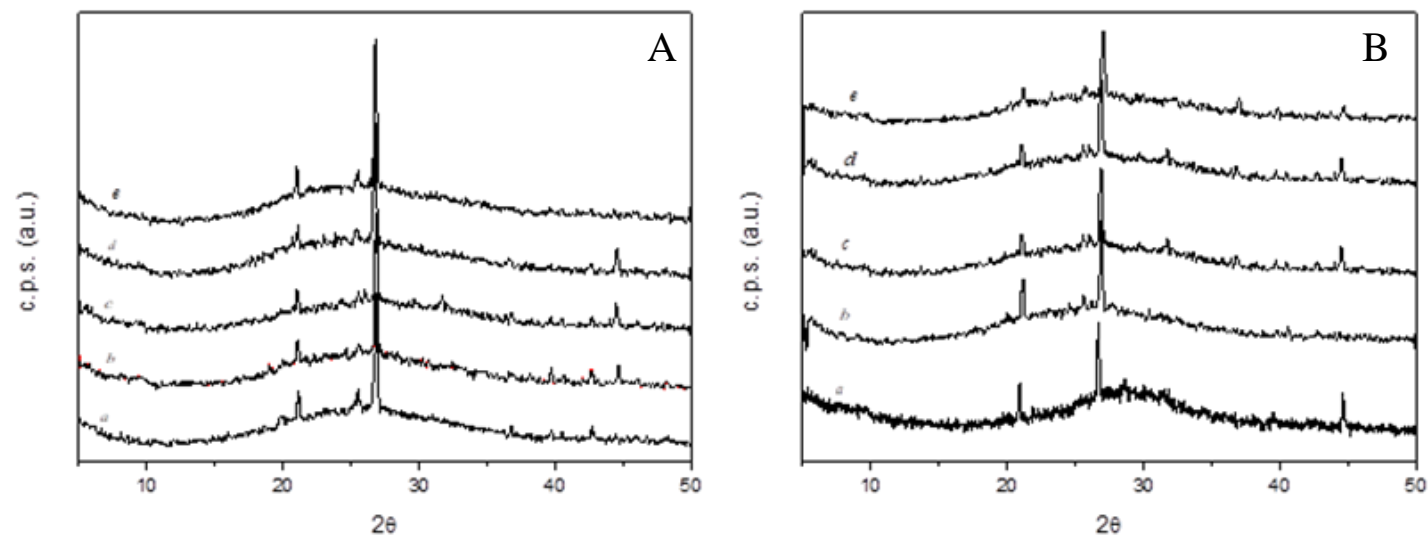

Figure 12. Diffractograms of geopolymeric mortars with (A) $0 \%$ wt of FBA and (B) $30 \%$ wt of FBA at: (a) as is and after thermal treatment at (b) $200{ }^{\circ} \mathrm{C}$; (c) $400{ }^{\circ} \mathrm{C}$; (d) $600{ }^{\circ} \mathrm{C}$ ); (e) $700{ }^{\circ} \mathrm{C}$.

All of the specimens appear essentially amorphous to XRD, with peaks from crystalline phases in parent materials and with no evidence of new crystalline phases being formed during thermal cycles, regardless of the amount of metakaolin replacement. Furthermore, with the increasing of temperature, quartz peaks become less pronounced, possibly reflecting a degree of dissolution under the temperature and alkaline conditions [30].

All of the above findings contribute to the loss of mechanical properties of the produced mortars after the thermal cycles. Compression strength measurements, reported in Figure 13, show an overall loss of about $80 \%$ of the initial value, regardless of the amount of metakaolin replacement. However, it must be pointed out that all of the specimens retained their cohesiveness during thermal treatments. 


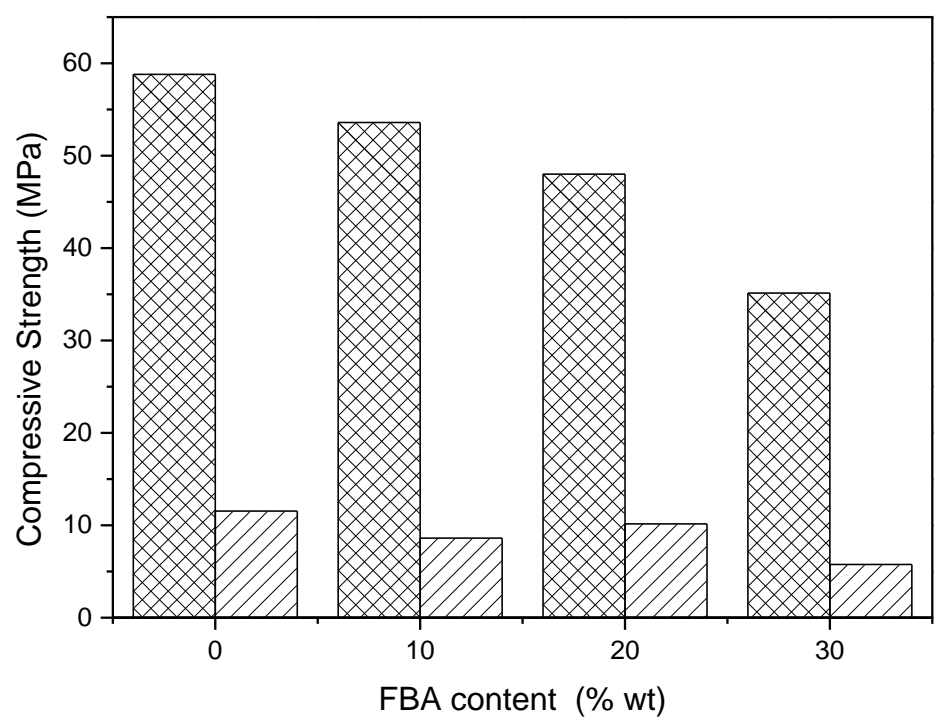

Figure 13. Compressive strength at different FBA contents at $30^{\circ} \mathrm{C}$ and after thermal treatments up to $700{ }^{\circ} \mathrm{C}$.

\section{Conclusions}

The results acquired throughout the present investigation allow deriving the following conclusions:

1. The inclusion of FBA as a partial replacement of metakaolin in geopolymer mortars results in a proportional increasing of workability. This behavior can be ascribed to both an increased rate in the dissolution of metakaolin due to both the higher alkalinity of the reaction mixes containing FBA their greater average particles size than metakaolin.

2. Weight ratio (metakaolin + FBA) / alkali silicate solution (dry basis) increases from 1.35/1 when only metakaolin is used to $1.7: 1$ when $30 \%$ wt of FBA is used.

3. All of the manufactured geopolymeric mortars show at XRD analysis the characteristic broad hump centered at approximately $28^{\circ} 2 \theta$, regardless of FBA content. SEM analysis reveals that geopolymers mortars with only metakaolin show a dense and continuous gel-like matrix with few clear particles or particle boundaries, while geopolymers mortars with FBA show a more porous and patchy matrix.

4. The use of FBA at a level of replacement of higher than $10 \%$ wt affects the mechanical properties of the geopolymeric mortar, reducing proportionally the compressive and flexural strength of the mortars, for all curing times. Nevertheless, a compression strength of more than $35 \mathrm{MPa}$ is still obtained with a replacement of $30 \%$ wt of metakaolin.

5. Mortars containing FBA show higher sorptivities values. This suggests that FBA alters the structure of the pores.

6. The inclusion of FBA slightly increases both the drying shrinkage, due to a higher porosity.

7. All of the hardened mortars, after thermal treatments, show an overall loss of mechanical strength of about $80 \%$ of the initial value that can be attributed to the network strain and distortion due to dehydration and shrinkage, and to a degree of dissolution of quartz under the used temperatures and alkaline conditions.

Therefore, it can be concluded that FBA can be potentially used as partial replacement material in the production of metakaolin (MK) based geopolymeric mortars. Further investigations based on durability tests are ongoing.

Acknowledgments: The authors wish to thank "Materials Science Laboratory" (University of Calabria), funded with "Pon Ricerca e Competitività 2007/2013: PON01_01522 ECOFIBAR" for providing equipment to perform the experiments. 
Author Contributions: Sebastiano Candamano, conceived and designed the experiments; Sebastiano Candamano, Pierantonio De Luca and Patrizia Frontera analyzed the data; Sebastiano Candamano wrote the paper; Fortunato Crea made critical revisions.

Conflicts of Interest: The authors declare no conflict of interest.

\section{References}

1. Siddique, R. Waste Materials and By-Products in Concrete, 1st ed.; Springer-Verlag Berlin Heidelberg: Berlin, Germany, 2008; ISBN 978-3-540-74294-4.

2. Campbell, A.G. Recycling and disposing of wood ash. TAPPI J. 1990, 73, 141-143.

3. Etiegni, L.; Campbell, A.G. Physical and chemical characteristics of wood ash. Bioresour. Technol. 1991, 37, 173-178. [CrossRef]

4. Ochoa de Alda, J.A.G. Feasibility of recycling pulp and paper mill sludge in the paper and board industries. Resour. Conserv. Recycl. 2008, 52, 965-972. [CrossRef]

5. Frontera, P.; Candamano, S.; Iacobini, I.; Crea, F. Eco-efficient self-compacting concrete with silica sand waste. Adv. Mat. Inf. Technol. Process. 2014, 87, 205-212.

6. Candamano, S.; Crea, F.; Romano, D.; Iacobini, I. Workability, Strength and Drying Shrinkage of Structural Mortar Containing Forest Biomass Ash in Partial Replacement of Cement. Adv. Mat. Res. 2014, 1051, 737-742. [CrossRef]

7. Palomo, A.; Krivenko, P.; Garcia-Lodeiro, I.; Kavalerova, E.; Maltseva, O.; Fernández-Jiménez, A. A review on alkaline activation: New analytical perspectives. Mater. Construcc. 2014, 64, 022. [CrossRef]

8. Abdalqader, A.F.; Jin, F.; Al-Tabbaa, A. Development of greener alkali-activated cement: Utilisation of sodium carbonate for activating slag and fly ash mixtures. J. Clean. Prod. 2014, 113, 66-75. [CrossRef]

9. Provis, J.L.; van Deventer, J.S.J. Alkali Activated Materials State-of-the-Art Report, RILEM TC 224-AAM; Springer Netherlands: Dordrecht, Netherlands, 2014; pp. 59-85.

10. Pacheco-Torgal, F.; Labrincha, J.A.; Leonelli, C.; Palomo, A.; Chindaprasirt, P. Handbook of Alkali-Activated Cements, Mortars and Concretes; Woodhead Publishing Series in Civil and Structural Engineering: Number 54; Woodhead Publishing: Cambridge, UK, 2015; pp. 19-43.

11. O'Connor, S.J.; MacKenzie, K.J.D.; Smith, M.; Hanna, J. Ion exchange in the charge-balancing sites of aluminosilicate inorganic polymers. J. Mater. Chem. 2010, 20, 10234-10240. [CrossRef]

12. Bortnovsky, O.; Dědeček, J.; Tvarůžková, Z.; Sobalík, Z. Metal ions as probes for characterization of geopolymer materials. J. Am. Ceram. Soc. 2008, 91, 3052-3057. [CrossRef]

13. Sazama, P.; Bortnovsky, O.; Dědeček, J.; Tvarůžková, Z.; Sobalík, Z. Geopolymer based catalysts-new group of catalytic materials. Catal. Today 2011, 164, 92-99. [CrossRef]

14. Miccio, F.; Natali, A.; Natali Murri, A.; Landi, E. Synthesis and characterization of geopolymer oxygen carriers for chemical looping combustion. Appl. Energy 2017, 194, 136-147. [CrossRef]

15. Candamano, S.; Frontera, P.; Macario, A.; Aloise, A.; Crea, F. New material as Ni-support for hydrogen production by ethanol conversion. Adv. Mat. Inf. Technol. Process. 2014, 87, 115-121.

16. Li, L.; Wang, S.; Zhu, Z. Geopolymeric adsorbents from fly ash for dye removal from aqueous solution. J. Colloid Interface Sci. 2006, 300, 52-59. [CrossRef] [PubMed]

17. Guo, B.; Pan, D.; Liu, B.; Volinsky, A.A.; Fincan, M.; Du, J.; Zhang, S. Immobilization mechanism of Pb in fly ash-based geopolymer. Constr. Build. Mater. 2017, 34, 123-130. [CrossRef]

18. Lamuta, C.; Candamano, S.; Crea, F.; Pagnotta, L. Direct piezoelectric effect in geopolymeric mortars. Mater. Des. 2016, 107, 57-64. [CrossRef]

19. Candamano, S.; Frontera, P.; Macario, A.; Crea, F.; Nagy, J.B.; Antonucci, P.L. Preparation and characterization of active Ni-supported catalyst for syngas production. Chem. Eng. Res. Des. 2015, 96, 78-86. [CrossRef]

20. UNI EN 1015-3:2007 Consistency of Wet Mortar. Available online: https:/ /infostore.saiglobal.com/store/ details.aspx?ProductID=610562 (accessed on 11 September 2017).

21. UNI-EN 196-1:2005 Methods of Testing Cement-Part 1: Determination of Strength. Available online: https: / / infostore.saiglobal.com/en-au/Standards/UNI-EN-196-1-2005-583689/ (accessed on 11 September 2017).

22. UNI EN 1015-18:2004 Methods of Test For Mortar For Masonry-Determination Of Water Absorption Coefficient Due To Capillary Action Of Hardened Mortar. Available online: https:/ /infostore.saiglobal.com/ store/details.aspx?ProductID=640959 (accessed on 11 September 2017). 
23. Sousa-Coutinho, J. The combined benefits of CPF and RHA in improving the durability of concrete structures. Cem. Concr. Compos. 2003, 25, 51-59. [CrossRef]

24. Duxson, P.; Fernandez-Jimenez, A.; Provis, J.L.; Lukey, G.C.; Palomo, A.; Van Deventer, J.S.J. Geopolymer technology: The current state of the art. J. Mater. Sci. 2007, 42, 2917-2933. [CrossRef]

25. Weng, L.; Sagoe-Crentsil, K. Dissolution processes, hydrolysis and condensation reactions during geopolymer synthesis: Part I-Low Si/Al ratio systems. J. Mater. Sci. 2007, 42, 2997-3006. [CrossRef]

26. Sagoe-Crentsil, K.; Weng, L. Dissolution processes, Hydrolysis and condensation reactions during geopolymer synthesis: Part II. High Si/Al ratio systems. J. Mater. Sci. 2007, 42, 3007-3014. [CrossRef]

27. Sabir, B.B.; Wild, S.; O'farrel, M.A. Water sorptivity test for mortar and concrete. Mater. Struct. 1998, 31, 568-574. [CrossRef]

28. Ohdaira, E.; Masuzawa, N. Water content and its effect on ultrasound propagation in concrete-The possibility of NDE. Ultrasonics 2000, 38, 546-552. [CrossRef]

29. Duxson, P.; Lukey, G.C.; Van Deventer, J.S.J. The effect of alkali metal type and silicate concentration on the thermal stability of geopolymers Geopolymer. Green Chemistry and Sustainable Development Solutions. In Proceedings of the World Congress Geopolymer, Perth, Australia, 28-29 September 2005; pp. 189-193.

30. Barbosa, V.F.F.; MacKenzie, K.J.D. Thermal behaviour of inorganic geopolymers and composite derived from sodium polysialate. Mater. Res. Bull. 2003, 38, 319-331. [CrossRef]

(C) 2017 by the authors. Licensee MDPI, Basel, Switzerland. This article is an open access article distributed under the terms and conditions of the Creative Commons Attribution (CC BY) license (http:/ / creativecommons.org/licenses/by/4.0/). 